\title{
Chapter 4 \\ Climate Catastrophes as a Sum of Known Risks
}

\author{
Francisco Estrada
}

\begin{abstract}
An ever-increasing body of research has warned for decades about the impacts of climate change on agriculture, health, flooding, economy, among many others and provided information about when and where these impacts could be larger. Are societies prepared for these expected 'white-swans', particularly in the context of a high degree of interconnectedness in Nature and in society? I borrow from the development of the Covid-19 pandemic to illustrate this view. Influenza pandemics have been foreseen decades before, but the characteristics of the virus and the socioeconomic links have made it into the global crisis that it had become in 2020 .
\end{abstract}

\subsection{Introduction}

The Covid-19 pandemic immediate message is that all countries are much more vulnerable to white-swan type of events and at much higher risk than previously thought. While initially a problem and its consequences may be foreseeable, the properties and interactions of complex natural and human systems can transform, amplify and transmit shocks in unexpected and unpredictable ways. Unpredictable events with major consequences, known as black swans, - or at least long, dark shadows from white swans - can arise as the outcome of otherwise predictable, manageable events.

This holds a lesson for the problem of climate change, which is one of the systemic socioenvironmental challenges that will pose more complex, uncertain and highly correlated problems in this century. The literature strongly suggests not only predictable impacts across natural and human systems, but the existence of ontological uncertainty and the possibility of surprises. The current pandemic should help to better gauge how confident one should be about current estimates of the magnitude of the impacts of global socioenvironmental issues.

\footnotetext{
F. Estrada $(\bowtie)$

Universidad Nacional Autónoma de México \& Vrije Universiteit,

Amsterdam, The Netherlands

e-mail: feporrua@atmosfera.unam.mx
} 


\subsection{Difficulties in Grasping the Scale and Impact of the Problem}

For much of the media, decision-makers and the general public, it is difficult to grapple with the climate problem. And, as argued here, there are good reasons for that. Climate change is a "wicked" problem that does not easily lends itself to be simplified in such a way that becomes easy to understand, communicate, much less to create policy for and to implement practical strategies to tackle it. It is a systemic problem and thus there is no simple way to characterize what its boundaries are; it is a long-memory problem for which current actions have considerable bearing in temporal scales we suffer from strong cognitive biases; it is riddled with epistemic uncertainty blurring our view not only of distant horizons, but the present and even the past in terms of data, knowledge about physics of climate and relevant aspects of the systems being affected by it, such as their sensitivity, coping and adaptation capacities. These difficulties can foster a wide range of contrasting beliefs and narratives that can lead to divergent perceptions of risk that polarize society and policymakers alike about climate policy. However, a good part of the basic ideas behind these opposing narratives share, without realizing it, similar biases.

Significant changes in global climate occur on timescales of centuries. However, while some physical aspects of climate change are "slow", such as the accumulation of greenhouse gases in the atmosphere, sea level rise and the warming of the deep oceans, this is not true for all physical aspects of climate change, nor for all spatial scales or the variety of impacts occurring over natural and human systems. Some estimates suggest that, at the global scale, the impacts of climate change during the last decades of the twentieth century became comparable in magnitude to those of natural climate variability (Estrada et al., 2017b). Damages from climate change are a function of changes in hazard, but also of a diversity of factors determining vulnerability, coping and adaptation capacities (Estrada et al., 2019; Field et al., 2012). All these are highly heterogeneous across and within regions and societies, and characterizing climate change as a "slow" problem to be worried about only in the far future may not be accurate for a significant part of the world's population (Adler et al., 2017; Ignjacevic et al., 2020; Ricke et al., 2018; Tol, 2009). Moreover, this view fails to accurately reflect the current understanding about trends in some extreme events (Field et al., 2012; Stott, 2016), as well as the existence of evidence but lack of consensus in some others, such as changes in economic damages from hurricanes and tropical storms (Botzen et al., 2020; Estrada et al., 2015b; Grinsted et al., 2019; Nordhaus, 2010), and the limited information we have about probabilities and thresholds that may trigger climate catastrophes (Cheng et al., 2013).

The ratification of the Paris Agreement by the vast majority of countries shows the existence of a consensus about the seriousness of the climate change problem and the need to reduce the associated risks (Lawrence \& Schäfer, 2019; 
Schellnhuber et al., 2016). Large uncertainties exist about the political willingness, feasibility and costs for the required stringent mitigation actions (Cox et al., 2018; Millar et al., 2017; Rogelj et al., 2018). The lack of results from international climate policy during the past 30 years suggests that while in the political discourse climate change occupies a high priority, the urgency has not permeated into the realm of actions so much. The current state of global climate policy can justifiably foster pessimistic expectations about the future. This view has the realism of the catastrophic impacts climate change and political paralysis can bring, but could underestimate the mechanisms of the civil society to bring political change, rapid shifts in technological trends and economic opportunities for a cleaner and more sustainable development (Zhenmin \& Espinosa, 2019), as well as the abilities of natural and human systems to deal with change and challenges. Technology and education can help coping with, and adapting to, some of the foreseeable consequences of climate change (Anthoff \& Tol, 2012; Haer et al., 2018; Tol et al., 2007). However, as argued below, probably the main risk comes from the interactions of concurrent problems that in the context of complex systems can overcome our capacities to cope and adapt and lead to potential catastrophes.

The opinion on the ontology of the climate change problem is not just an academic problem. The way we see the world influences how we choose to deal with it. In such a politically polarized world we live in nowadays, this can end up in some circles as a cartoonish conundrum: on the one hand, if the climate problem is slowmoving and non-catastrophic, societies do not need to adapt quickly and $\mathrm{CO}_{2}-$ emissions do not have to be brought down that fast. It may even be thought that cleaner production and emission standards can be postponed for decades. On the other hand, if catastrophic events are just around the corner, we should stop doing what we are doing and put the reduction of greenhouse gases above all other priorities that we might have. These differences are frequently debated but the other part of the equation defining climate change consequences is often forgotten: how well are societies prepared to deal with the catastrophic and non-catastrophic risks and impacts?

There are fundamental differences between climate change and pandemic risks but also striking similarities regarding its causes, consequences and the behavioral biases societies suffer (Botzen et al., 2021). Pandemics are experienced as discrete acute events, climate change is commonly conceived as a longterm, chronic problem that gets worse over time and that is accompanied by acute, discrete events, such as extreme realizations of weather and climate (Field et al., 2012; Hoegh-Guldberg et al., 2018). These problems are not independent as they share common drivers: anthropogenic perturbation of natural systems seem to be imposing an accelerating trend to the emergence and reemergence of infectious diseases and increase their transmission (Brooks \& Boeger, 2019; Morens \& Fauci, 2020; Watts et al., 2020). Despite their differences, we can learn valuable lessons from Covid-19 about our response to global challenges such as climate change. 


\subsection{The Apparent Predictability and Manageability of Climate Change}

The consequences of climate change on natural and human systems have been studied for more than 40 years, and although the existence of ontological uncertainty (unknown unknows) and the possibility of surprises are recognized, governments and societies treat this as problem that can be handled within the boundaries of standard approaches and methods, timeframes and relatively small additional efforts. A considerable portion of the peer-reviewed estimates suggest this phenomenon may have a modest impact on the world's economy and thus stringent mitigation actions are not justified (Mendelsohn, 2010; Tol, 2009).

While accounting for the possibility of climate catastrophes, nonlinearities and tipping points has shown these estimates to rise, they seem not to tilt the balance enough for triggering significantly larger mitigation efforts (Anthoff et al., 2016; Colt \& Knapp, 2016; Mendelsohn et al., 2016; Nordhaus, 2011; Weitzman, 2009). Ethical and distributional concerns between and within regions, long-run consequences and modelling limitations have also been brought forward as reasons to support higher levels of concern and action (Estrada et al., 2015a; Stern, 2013; Tol, 2018). However, leading economic models suggest allowing an increase of $3.5^{\circ} \mathrm{C}$ in global temperatures at the end of this century could be the optimal climate policy (Nordhaus, 2018). It is worth noting that such estimate accounts for the possibility of occurrence of climate catastrophes. However, an increasing body of evidence suggests that the results of existing economic models may reveal more about the limitations of current research methods and oversimplified systems' representations, than of the severity of climate change consequences (Botzen et al., 2020; Estrada et al., 2015a, 2017a; Stern, 2013; Van den Bergh \& Botzen, 2014; Van den Bergh \& Botzen, 2015).

\subsection{The Corona Crisis as a Harbinger of Climate Risks}

Because of the high connectivity of the modern world, the current Covid-19 pandemic was not only foreseeable but expected (Contini et al., 2020; Scarpino \& Petri, 2019). Scientists have warned for influenza pandemics before, and earlier virus outbreaks such as SARS and Swine flu have shown that local outbreaks of a novel virus can quickly spread globally. The interconnection of the modern world is made possible by airplanes and global shipping. The means of global transportation facilitate trade, the exchange of ideas and tourism, but also the spreading of diseases.

Because we were warned, the Covid-19 pandemic cannot be considered as a 'Black Swan' type of event. These events are defined by three main conditions: (1) being outside the realm of regular expectation and probability theory, (2) they produce impacts of historic proportions and; (3) in retrospect they seem predictable and explainable and thus their unpredictable nature is incorrectly dismissed 
(Aven, 2013; Taleb, 2007). Although, given the observed outcomes in terms of health and socioeconomic impacts, this event is of historic proportions, current scientific knowledge and historic data indicates that this pandemic violates the first and third conditions. A vast amount of scientific literature warned about the occurrence of pandemic events (Cheng et al., 2007; Fan et al., 2018; Hill et al., 2017; Poland et al., 2007), to the extent such events have even been absorbed by pop-culture for decades. However, its global impact has been much larger than expected, changing how people live, including their social interactions and the economy. These effects are projected to be highly persistent and, in some cases, even permanent, leading to the perception that the world has to transit to a "new normality" in which some aspects in the post-pandemic life could be fundamentally different in commerce, tourism, mobility and a wide range of social interactions (De Vos, 2020).

At the time of writing this text, globally more than 65 million people have been confirmed as infected, more than 1.5 million people have died from Covid-19, health systems in most countries have faced severe challenges to manage the emergency, there have been considerable shortages of medical supplies and equipment, and a significant share of the world's population is under lockdown or quarantine, pushing the economy to an unparalleled standstill. The resulting socioeconomic impacts are expected to be unprecedented in recent history and their long-run effects are unknown.

Covid-19 illustrates that socioenvironmental problems do not present themselves in isolation. Its effects have been painfully amplified by underlying systemic socioeconomic and environmental issues, such as the fragile state of health systems, the inadequacy of governmental measures for prevention and control, poverty and inequality, environmental degradation, air quality among many more. This initially foreseeable problem for which we should have been prepared for, was transformed into a much less predictable, manageable and containable situation that involves unknow consequences and derivations in the political, social and economic realms at the local, regional and global scales. Learning from this experience is of outmost importance for facing the global socioenvironmental problems that we know will endure this century. One of these challenges is global warming.

\subsection{Catastrophes as Cascades of Foreseeable Problems}

Climate change represents a much more complicated problem since it is expected to affect a wide range of aspects of human and natural systems simultaneously, and thus creating highly correlated risks that will be very hard to manage or hedge against. The compound risk of climate change and of other environmental and social problems that occur simultaneously (e.g., health, air pollution, urban heat island, institutional fragility, social inequality and poverty) is hardly quantifiable and predictable. Moreover, current approaches in natural and social sciences are only starting to be prepared for the study of this type of wide ranging, simultaneous and systemic problems. 
Governments and society are much less prepared for facing such problems, in part due to knowledge gaps and lack of a more comprehensive representation of risk. Dealing with several white and a few black swans at the same time may topple otherwise sufficient and adequate governmental and social capacities. Adequate impact and risk assessment are necessary for informing decision-making about critical issues and for developing effective risk management and risk reduction strategies (Dillon et al., 2009; Grossi \& Kunreuther, 2005; Pollard et al., 2008). This is particularly challenging when it involves the analysis and modelling of complex systems and their interactions, which are characterized by fragmented information, incomplete knowledge and sometimes by what has been described as "unknown unknowns" (Oreskes et al., 1994; Spiegelhalter \& Riesch, 2011; Walker et al., 2013). Such is the case of some of the most pressing socioenvironmental problems humanity is currently facing and will continue to do so for at least this century.

Catastrophic events are likely to be more frequent in a world in which socioenvironmental systems are pushed to their limits. Economic development and high levels of socioeconomic connectivity can quickly transform local shocks into global issues (Barnosky et al., 2011; Hansen et al., 2011; Lenton et al., 2019; Rockström et al., 2009). This has been illustrated by several financial and economic crises over the past decades, by terrorism which acts exclusively at local scales but that translates to global policies, also by environmental issues such as the impact of plastics on the global ocean, and of course, pollution and climate change.

One of the attributes defining Black Swans is that it is unpredictable because nothing in the past can convincingly point to its possibility (Taleb, 2007), or more broadly "nothing in our knowledge can convincingly point to its possibility" (Aven, 2013). Thus, the existence of a black swan depends on who is experiencing it and in their scientific and technical capacities which affect the ability to generate coordinated and coherent governmental and societal response. This also holds for the length and darkness of a shadow a single white swan or a flock of them could cast.

Given the high levels of socioeconomic connectivity such events will not be contained by political boundaries. As such, global risk reduction strategies should include closing the gaps in development, education and technology within and between countries. In the case of climate change and other global socioenvironmental problems, empirical or observational examples that may serve as analogues which could help guiding decision-making will be much more scarce or impossible. Moreover, the horizon needed to consider for policymaking is much longer than for a pandemic such as Covid-19 and the delay between the time actions are implemented and their results are seen may be quite long.

Information for supporting decision-making may also strongly depend on models with incomplete knowledge, substantial assumptions and high-levels of uncertainty. These characteristics can generate divergent perceptions about the problem and the correct way of dealing with it among different actors, as well as ambiguity about what is known or knowable. Such characteristics can introduce more complexity for decision-making, higher political costs and difficulties for generating coordinated and coherent responses and thus amplify risks and hamper effective action and optimal strategies. This has been repeatedly illustrated by the lack of success in international climate negotiations. 


\subsection{Conclusion}

Addressing problems such as climate change and pandemics require global cooperation and coordination. Covid-19 provides us with an example of a predictable, but rare event for which we should be better prepared next time. In this chapter, I have argued that the lessons of the pandemic can be extended to the problem of climate change: catastrophic outcomes might result from predictable events and processes. It is the complex interaction between predictable events, the "White Swans", that can lead to otherwise unpredictable compound events, the "Black Swan". This pandemic should help us better assess how confident we should be about current estimates about the consequences of global socioenvironmental issues.

Luckily for mankind, globalization has not just made the spread of viruses easier, but also the means of communication. Information spreads just as well, so that news about virus outbreaks, preventive measures and therapies can be coordinated on the same global scale. After the onset of the Covid-19 pandemic, medical researchers worldwide as well as pharmaceutical companies join forces to come up with a vaccine. Whereas the traditional development of vaccines takes at least 10-15 years, the current prospects for a Corona vaccine are such that it might be available within 9 months from the emergence of the virus. That is a more than ten-fold increase in speed, spurred on by the seriousness of a worldwide catastrophe. This is a hopeful lesson for climate policy.

The world is currently much better equipped with technology, knowledge and science than in any previous time in history. This has made and will continue to make societies less vulnerable and more able to respond and adapt to environmental problems. However, we should also learn that problems that may be predictable and manageable in isolation, their interaction with other issues and natural and human systems may end up producing unpredictable, very costly and perhaps hardly manageable global issues.

\section{References}

Adler, M., Anthoff, D., Bosetti, V., et al. (2017). Priority for the worse-off and the social cost of carbon. Nature Climate Change, 7, 443-449.

Anthoff, D., \& Tol, R. S. J. (2012). Schelling's conjecture on climate and development: A test. In Climate change and common sense: Essays in honour of tom schelling (pp. 260-274). Oxford University Press.

Anthoff, D., Estrada, F., \& Tol, R. S. J. (2016). Shutting down the thermohaline circulation. American Economic Review, 106(5), 602-606.

Aven, T. (2013). On the meaning of a black swan in a risk context. Safety Science, 57, 44-51.

Barnosky, A. D., Matzke, N., Tomiya, S., et al. (2011). Has the Earth's sixth mass extinction already arrived? Nature, 471, 51-57.

Botzen, W. J. W., Estrada, F., \& Tol, R. S. J. (2020). Methodological issues in natural disaster loss normalisation studies. Environmental Hazards, 20, 1-4. 
Botzen, W. J. W., Duijndam, S., \& van Beukering, P. (2021). Lessons for climate policy from behavioral biases towards COVID-19 and climate change risks. World Development, 137, 105214.

Brooks, D. R., \& Boeger, W. A. (2019). Climate change and emerging infectious diseases: Evolutionary complexity in action. Current Opinion in Systems Biology, 13, 75-81.

Cheng, V. C. C., Lau, S. K. P., Woo, P. C. Y., \& Kwok, Y. Y. (2007). Severe acute respiratory syndrome coronavirus as an agent of emerging and reemerging infection. Clinical Microbiology Reviews, 20(4), 660-694.

Cheng, W., Chiang, J. C. H., Zhang, D., et al. (2013). Atlantic meridional overturning circulation (AMOC) in CMIP5 models: RCP and historical simulations. Journal of Climate, 26(18), 7187-7197.

Colt, S. G., \& Knapp, G. P. (2016). Economic effects of an ocean acidification catastrophe. American Economic Review, 106(5), 615-619.

Contini, C., Di Nuzzo, M., Barp, N., et al. (2020). The novel zoonotic COVID-19 pandemic: An expected global health concern. The Journal of Infection in Developing Countries, 14(03), 254-264.

Cox, P. M., Huntingford, C., \& Williamson, M. S. (2018). Emergent constraint on equilibrium climate sensitivity from global temperature variability. Nature, 553, 319-322.

De Vos, J. (2020). The effect of COVID-19 and subsequent social distancing on travel behavior. Transportation Research Interdisciplinary Perspectives, 5, 100121.

Dillon, R. L., Liebe, R. M., \& Bestafka, T. (2009). Risk-based decision making for terrorism applications. Risk Analysis, 29, 321-335.

Estrada, F., Tol, R. S. J., \& Gay-García, C. (2015a). The persistence of shocks in GDP and the estimation of the potential economic costs of climate change. Environmental Modelling \& Software, 69, 155-165.

Estrada, F., Wouter Botzen, W. J. W., \& Tol, R. S. J. (2015b). Economic losses from US hurricanes consistent with an influence from climate change. Nature Geoscience, 8, 880-885.

Estrada, F., Botzen, W. J. W., \& Tol, R. S. J. (2017a). A global economic assessment of city policies to reduce climate change impacts. Nature Climate Change, 7(6), 403-406.

Estrada, F., Tol, R. S. J., \& Botzen, W. J. W. (2017b). Global economic impacts of climate variability and change during the 20th century. PLoS One, 12, e0172201.

Estrada, F., Tol, R. S. J., \& Botzen, W. J. W. (2019). Extending integrated assessment models' damage functions to include adaptation and dynamic sensitivity. Environ Model Softw, 121, 104504.

Fan, V. Y., Jamison, D. T., \& Summers, L. H. (2018). Pandemic risk: How large are the expected losses? Bulletin of the World Health Organization, 96(2), 129.

Field, C. B., Barros, V., Stocker, T. F., \& Dahe, Q. (Eds.). (2012). Managing the risks of extreme events and disasters to advance climate change adaptation: Special report of the intergovernmental panel on climate change. Cambridge University Press.

Grinsted, A., Ditlevsen, P., \& Christensen, J. H. (2019). Normalized US hurricane damage estimates using area of total destruction, 1900-2018. Proceedings of the National Academy of Sciences, 116(48), 23942-23946.

Grossi, P., \& Kunreuther, H. (2005). Catastrophe modeling: A new approach to managing risk (Vol. 25). Springer Science \& Business Media.

Haer, T., Botzen, W. W., Van Roomen, V., Connor, H., Zavala-Hidalgo, J., Eilander, D. M., \& Ward, P. J. (2018). Coastal and river flood risk analyses for guiding economically optimal flood adaptation policies: A country-scale study for Mexico. Philosophical Transactions of the Royal Society A: Mathematical, Physical and Engineering Sciences, 376(2121), 20170329.

Hansen, J., Sato, M., Kharecha, P., \& von Schuckmann, K. (2011). Earth's energy imbalance and implications. Atmospheric Chemistry and Physics, 11(24), 13421.

Hill, E. M., Tildesley, M. J., \& House, T. (2017). Evidence for history-dependence of influenza pandemic emergence. Scientific Reports, 7, 43623.

Hoegh-Guldberg, O., Jacob, D., Bindi, M., Brown, S., Camilloni, I., Diedhiou, A., ... Hijioka, Y. (2018). Impacts of 1.5 C global warming on natural and human systems. Global warming of $1.5^{\circ}$ C. An IPCC special report. IPCC. 
Ignjacevic, P., Botzen, W. W., Estrada, F., Kuik, O., Ward, P., \& Tiggeloven, T. (2020). CLIMRISKRIVER: Accounting for local river flood risk in estimating the economic cost of climate change. Environmental Modelling \& Software, 132, 104784.

Lawrence, M. G., \& Schäfer, S. (2019). Promises and perils of the Paris agreement. Science, 364(6443), 829-830.

Lenton, T. M., Rockström, J., Gaffney, O., Rahmstorf, S., Richardson, K., Steffen, W., \& Schellnhuber, H. J. (2019). Climate tipping points-Too risky to bet against. Nature, 575, 592-595.

Mendelsohn, R. (2010). Climate change and economic growth. Globalization and Growth, 60, 24.

Mendelsohn, R., Prentice, I. C., Schmitz, O., Stocker, B., Buchkowski, R., \& Dawson, B. (2016). The ecosystem impacts of severe warming. American Economic Review, 106(5), 612-614.

Millar, R. J., Fuglestvedt, J. S., Friedlingstein, P., Rogelj, J., Grubb, M. J., Matthews, H. D., ... Allen, M. R. (2017). Emission budgets and pathways consistent with limiting warming to 1.5 C. Nature Geoscience, 10(10), 741-747.

Morens, D. M., \& Fauci, A. S. (2020). Emerging pandemic diseases: How we got to COVID-19. Cell, 182, 1077-1092.

Nordhaus, W. D. (2010). The economics of hurricanes and implications of global warming. Climate Change Economics, 1(01), 1-20.

Nordhaus, W. D. (2011). The economics of tail events with an application to climate change. Review of Environmental Economics and Policy, 5(2), 240-257.

Nordhaus, W. (2018). Projections and uncertainties about climate change in an era of minimal climate policies. American Economic Journal: Economic Policy, 10(3), 333-360.

Oreskes, N., Shrader-Frechette, K., \& Belitz, K. (1994). Verification, validation, and confirmation of numerical models in the earth sciences. Science, 263(5147), 641-646.

Poland, G. A., Jacobson, R. M., \& Targonski, P. V. (2007). Avian and pandemic influenza: An overview. Vaccine, 25(16), 3057-3061.

Pollard, S. J., Davies, G. J., Coley, F., \& Lemon, M. (2008). Better environmental decision making-Recent progress and future trends. Science of the Total Environment, 400(1-3), 20-31.

Ricke, K., Drouet, L., Caldeira, K., \& Tavoni, M. (2018). Country-level social cost of carbon. Nature Climate Change, 8(10), 895-900.

Rockstrom, J., Steffen, W., Noone, K., Persson, A., Chapin, F. S., III, Lambin, E., T. M. Lenton, T. M., Scheffer, M., Folke, C., Schellnhuber, H., Nykvist, B., De Wit, C. A., Hughes, T., van der Leeuw, S., Rodhe, H., Sorlin, S., Snyder, P. K., Costanza, R., Svedin, U., Falkenmark, M., Karlberg, L., Corell, R. W., Fabry, V. J., Hansen, J., Walker, B., Liverman, D., Richardson, K., Crutzen, P., \& Foley, J. (2009). Planetary boundaries:exploring the safe operating space for humanity. Ecology and Society 14(2), 32.

Rogelj, J., Popp, A., Calvin, K. V., Luderer, G., Emmerling, J., Gernaat, D., ... Krey, V. (2018). Scenarios towards limiting global mean temperature increase below $1.5 \mathrm{C}$. Nature Climate Change, 8(4), 325.

Scarpino, S. V., \& Petri, G. (2019). On the predictability of infectious disease outbreaks. Nature Communications, 10(1), 1-8.

Schellnhuber, H. J., Rahmstorf, S., \& Winkelmann, R. (2016). Why the right climate target was agreed in Paris. Nature Climate Change, 6(7), 649-653.

Spiegelhalter, D. J., \& Riesch, H. (2011). Don't know, can't know: Embracing deeper uncertainties when analysing risks. Philosophical Transactions of the Royal Society A: Mathematical, Physical and Engineering Sciences, 369(1956), 4730-4750.

Stern, N. (2013). The structure of economic modeling of the potential impacts of climate change: Grafting gross underestimation of risk onto already narrow science models. Journal of Economic Literature, 51(3), 838-859.

Stott, P. (2016). How climate change affects extreme weather events. Science, 352(6293), $1517-1518$.

Taleb, N. N. (2007). The black swan: The impact of the highly improbable (Vol. 2). Random house. 
Tol, R. S. (2009). The economic effects of climate change. Journal of Economic Perspectives, 23(2), 29-51.

Tol, R. S. (2018). The economic impacts of climate change. Review of Environmental Economics and Policy, 12(1), 4-25.

Tol, R. S., Ebi, K. L., \& Yohe, G. W. (2007). Infectious disease, development, and climate change: A scenario analysis. Environment and Development Economics, 12(5), 687-706.

Van den Bergh, J. C., \& Botzen, W. J. (2014). A lower bound to the social cost of CO 2 emissions. Nature Climate Change, 4(4), 253-258.

Van den Bergh, J. C., \& Botzen, W. J. W. (2015). Monetary valuation of the social cost of CO2 emissions: A critical survey. Ecological Economics, 114, 33-46.

Walker, W. E., Lempert, R. J., \& Kwakkel, J. H. (2013). Deep uncertainty. In Encyclopedia of operations research and management science (pp. 395-402). Springer US.

Watts, N., Amann, M., Arnell, N., Ayeb-Karlsson, S., Beagley, J., Belesova, K., ... Capstick, S. (2020). The 2020 report of the lancet countdown on health and climate change: Responding to converging crises. The Lancet, 397, 129-170.

Weitzman, M. L. (2009). On modeling and interpreting the economics of catastrophic climate change. The Review of Economics and Statistics, 91(1), 1-19.

Zhenmin, L., \& Espinosa, P. (2019). Tackling climate change to accelerate sustainable development. Nature Climate Change, 9(7), 494-496.

Francisco Estrada is a researcher in the Climate and Society research group at the Center for Atmospheric Sciences of the Universidad Nacional Autónoma de México (UNAM) and the Coordinator of the Climate Change Research Program of UNAM. He is also a visiting researcher at the Department of Environmental Economics, Institute for Environmental Studies (IVM), Vrije Universiteit Amsterdam. He was a contributing author for the Working Group II of the IPCC's Fourth Assessment Report and expert reviewer for the Working Group II contribution for the IPCC's Fifth Assessment Report. He has participated and coordinated research projects on the assessment of the potential impacts of climate change in agriculture, the economics of climate change and also on the generation of regional climate change scenarios.

Open Access This chapter is licensed under the terms of the Creative Commons Attribution 4.0 International License (http://creativecommons.org/licenses/by/4.0/), which permits use, sharing, adaptation, distribution and reproduction in any medium or format, as long as you give appropriate credit to the original author(s) and the source, provide a link to the Creative Commons license and indicate if changes were made.

The images or other third party material in this chapter are included in the chapter's Creative Commons license, unless indicated otherwise in a credit line to the material. If material is not included in the chapter's Creative Commons license and your intended use is not permitted by statutory regulation or exceeds the permitted use, you will need to obtain permission directly from the copyright holder.

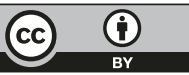

